\title{
Refining temperature measures in thermal/optical carbon analysis
}

\author{
J. C. Chow ${ }^{1}$, J. G. Watson ${ }^{1}$, L.-W. A. Chen ${ }^{1}$, G. Paredes-Miranda ${ }^{1}$, M.-C. O. Chang ${ }^{1}$, D. Trimble ${ }^{1}$, K. K. Fung ${ }^{2}$, \\ H. Zhang ${ }^{3}$, and J. Zhen $\mathbf{Y u}^{3}$ \\ ${ }^{1}$ Division of Atmospheric Sciences, Desert Research Institute, 2215 Raggio Parkway, Reno, NV 89512, USA \\ ${ }^{2}$ Atmoslytic Inc., 24801 Alexandra Ct., Calabasas, CA 91302, USA \\ ${ }^{3}$ Department of Chemistry, Hong Kong University of Science and Technology, Clear Water Bay, Hong Kong, China
}

Received: 2 May 2005 - Published in Atmos. Chem. Phys. Discuss.: 6 July 2005

Revised: 8 September 2005 - Accepted: 13 October 2005 - Published: 7 November 2005

\begin{abstract}
Thermal/optical methods have been widely used for quantifying total carbon (TC), organic carbon (OC), and elemental carbon (EC) in ambient and source particulate samples. Thermally defined carbon fractions have been used for source identification. Temperature precision in thermal carbon analysis is critical to the allocation of carbon fractions. The sample temperature is determined by a thermocouple, which is usually located in the oven near the sample. Sample and thermocouple temperature may differ owing to different thermal properties between the sample filter punch and the thermocouple, or inhomogeneities in the heating zone. Quick-drying temperature-indicating liquids (Tempil Inc., South Plainfield, NJ) of different liquefying points are used as temperature calibration standards. These consist of chemicals that change their appearance at specific temperatures and can be optically monitored to determine the sample temperature. Temperature measures were evaluated for three different models of carbon analyzers. Sample temperatures were found to differ from sensor temperatures by 10 to $50^{\circ} \mathrm{C}$. Temperature biases of 14 to $22^{\circ} \mathrm{C}$ during thermal analysis were found to change carbon fraction measurements. The temperature indicators allow calibration curves to be constructed that relate the sample temperature to the temperature measured by a thermocouple.
\end{abstract}

\section{Introduction}

Carbonaceous aerosol plays a major role in air pollution, visibility, health, and climate effects (e.g., Chow et al., 2005; Watson, 2002; Vedal, 1997; Jacobson, 2001). Atmospheric carbon consists of: organic carbon (OC, including various

Correspondence to: J. C. Chow

(judy.chow@dri.edu) organic compounds), elemental carbon (EC, or black carbon $[\mathrm{BC}] /$ soot, a non-volatile/light-absorbing carbon), and a small quantity of carbonate carbon (e.g., $\mathrm{CaCO}_{3}$; Chow and Watson, 2002; Cao et al., 2005)

Heating of liquid and solid materials with detection of the evolved gases has been used since the time of Lavoisier (1789) to determine their composition. Differential and evolved gas analyses were staples of the analytical chemist (MacKenzie, 1970) until the latter part of the 20th century when other instrumentation became available. Thermal evolution methods are still in widespread use today (e.g., Cadle and Groblicki, 1982; Huntzicker et al., 1982; Novakov, 1982; Cachier et al., 1989a, 1989b; Hitzenberger et al., 1999; Watson et al., 2005) to measure total carbon ( $\mathrm{TC}=\mathrm{OC}+\mathrm{EC}$ ) and fractions in suspended particles collected on filters. OC, $\mathrm{EC}$, and other carbon fractions are defined by the temperatures at which they evolve, sometimes in conjunction with optical detection of BC. Precise measures of the sample temperature are difficult to obtain owing to different locations and heating characteristics of the sample and the temperature sensor. This difference between sample and temperature sensors could be one of the causes of differences between $\mathrm{OC}$ and EC measurements by different laboratories applying similar thermal evolution methods (e.g., Currie et al., 2002; Schmid et al., 2001; Watson et al., 2005). These temperature differences may be especially important when data are compared from different networks such as the non-urban Interagency Monitoring of Protected Visual Environments network (IMPROVE, Chow et al., 1993, 2001, 2004a) and urban Speciation Trends Network (STN, Peterson and Richards, 2002) in the United States. Hundreds of thousands of carbon measurements have been acquired in these networks that are used for air quality planning and research purposes. Thermally-derived carbon fractions that are quite sensitive to

(C) 2005 Author(s). This work is licensed under a Creative Commons License. 
Table 1. Comparison of the IMPROVE, STN, and HKUST-3 thermal/optical analysis protocols.

\begin{tabular}{|c|c|c|c|c|}
\hline $\begin{array}{l}\text { Methods' } \\
\text { Carrier Gas }\end{array}$ & $\begin{array}{l}\text { Carbon } \\
\text { Fraction }\end{array}$ & $\begin{array}{l}\text { IMP_TOR/TOT }^{\mathrm{a}} \\
\text { Temperature, Time }\end{array}$ & $\begin{array}{l}\text { STN_TOT/TOR } \\
\text { Temperature, Time }\end{array}$ & $\begin{array}{l}\text { HKUST-3_TOT }^{\mathrm{a}} \\
\text { Temperature, Time }\end{array}$ \\
\hline He-Purge & & $30^{\circ} \mathrm{C}, 90 \mathrm{~s}$ & $30^{\circ} \mathrm{C}, 90 \mathrm{~s}$ & $30^{\circ} \mathrm{C}, 90 \mathrm{~s}$ \\
\hline $\mathrm{He}-1$ & OC1 & $120^{\circ} \mathrm{C}, 150-580 \mathrm{~s}^{\mathrm{c}}$ & $310^{\circ} \mathrm{C}, 60 \mathrm{~s}$ & $250^{\circ} \mathrm{C}, 150 \mathrm{~s}$ \\
\hline $\mathrm{He}-2$ & OC2 & $250^{\circ} \mathrm{C}, 150-580 \mathrm{~s}$ & $480^{\circ} \mathrm{C}, 60 \mathrm{~s}$ & $550^{\circ} \mathrm{C}, 150 \mathrm{~s}$ \\
\hline $\mathrm{He}-3$ & OC3 & $450^{\circ} \mathrm{C}, 150-580 \mathrm{~s}$ & $615^{\circ} \mathrm{C}, 60 \mathrm{~s}$ & $650^{\circ} \mathrm{C}, 150 \mathrm{~s}$ \\
\hline $\mathrm{He}-4$ & $\mathrm{OC} 4$ & $550^{\circ} \mathrm{C}, 150-580 \mathrm{~s}$ & $900^{\circ} \mathrm{C}, 90 \mathrm{~s}$ & $850^{\circ} \mathrm{C}, 110 \mathrm{~s}$ \\
\hline He-5 & & - & Cool Oven & Cool Oven \\
\hline $\mathrm{O}_{2} / \mathrm{He}-1^{\mathrm{b}}$ & EC1 & $550^{\circ} \mathrm{C}, 150-580 \mathrm{~s}$ & $600^{\circ} \mathrm{C}, 45 \mathrm{~s}$ & $650^{\circ} \mathrm{C}, 150 \mathrm{~s}$ \\
\hline $\mathrm{O}_{2} / \mathrm{He}-2$ & $\mathrm{EC} 2$ & $700^{\circ} \mathrm{C}, 150-580 \mathrm{~s}$ & $675^{\circ} \mathrm{C}, 45 \mathrm{~s}$ & $750^{\circ} \mathrm{C}, 150 \mathrm{~s}$ \\
\hline $\mathrm{O}_{2} / \mathrm{He}-3$ & EC3 & $800^{\circ} \mathrm{C}, 150-580 \mathrm{~s}$ & $750^{\circ} \mathrm{C}, 45 \mathrm{~s}$ & $850^{\circ} \mathrm{C}, 150 \mathrm{~s}$ \\
\hline $\mathrm{O}_{2} / \mathrm{He}-4$ & & - & $825^{\circ} \mathrm{C}, 45 \mathrm{~s}$ & $890^{\circ} \mathrm{C}, 150 \mathrm{~s}$ \\
\hline $\mathrm{O}_{2} / \mathrm{He}-5$ & & - & $920^{\circ} \mathrm{C}, 120 \mathrm{~s}$ & - \\
\hline
\end{tabular}

a IMPROVE_TOR: Thermal/optical reflectance analysis following the IMPROVE (Interagency Monitoring of Protected Visual Environments) protocol using DRI/OGC analyzers (Desert Research Institute, Reno, NV). IMPROVE_TOR does not advance from one temperature to the next until a well-defined carbon peak has evolved (Chow et al., 1993, 2001, 2004a). Filter reflectance is monitored throughout the analysis; pyrolyzed OC (OP) is defined as the carbon evolving between the introduction of oxygen $\left(\mathrm{O}_{2}\right)$ in the helium $(\mathrm{He})$ atmosphere and the return of reflectance to its initial value (the OC/EC split). OP is reported as a positive value if the reflection achieves its original value after the introduction of $\mathrm{O}_{2}$, and as a negative value if the reflection achieves its original value before $\mathrm{O}_{2}$ is introduced. In either case, OC equals $\mathrm{OC} 1+\mathrm{OC} 2+\mathrm{OC} 3+\mathrm{OC} 4+\mathrm{OP}$ and $\mathrm{EC}$ equals $\mathrm{EC} 1+\mathrm{EC} 2+\mathrm{EC} 3-\mathrm{OP}$. Eight well-defined fractions of carbon, including four OC fractions (OC1, OC2, OC3, and OC4), three EC fractions (EC1, EC2, and EC3), and OP are reported as part of the IMPROVE_TOR protocol.

IMPROVE_TOR/TOT: Same as the IMPROVE_TOR protocol but using a DRI Model 2001 thermal/optical carbon analyzer (Atmoslytic, Inc., Calabasas, CA). The DRI Model 2001 performs charring correction through both reflectance and transmittance, reported as OPR and OPT, respectively. Subsequently, OC and EC calculated from OPR (OPT) are referred to as OCR and ECR (OCT and ECT), respectively. STN_TOR/TOT: Thermal/optical transmission/reflectance analysis following the Speciation Trends Network (STN) protocol. Filter transmittance is monitored to split OC and EC (STN_TOT). With the DRI Model 2001 thermal/optical carbon analyzer, reflectance can also be recorded during the STN analyses. The protocol that uses STN temperature plateaus with a reflectance measurement is referred to as STN_TOR. The STN protocol has a short and fixed residence time per temperature plateau and cannot report distinguishable carbon fractions. The STN protocol is currently applied to the United States $\mathrm{PM}_{2.5}$ Speciation Trends Network.

HKUST-3_TOT: Thermal/optical transmission analysis following the HKUST-3 (Hong Kong University of Science and Technology, Clear Water Bay, Hong Kong, China) protocol using a Sunset Laboratory Carbon Aerosol Analysis Lab Instrument (Sunset Laboratory, Tigard, OR). The HKUST-3 transmittance protocol has a short and fixed residence time per temperature plateau and does not usually report distinguishable carbon fractions.

b $2 \% \mathrm{O}_{2}$ in He for IMPROVE and STN protocols, and $1 \% \mathrm{O}_{2}$ in He for HKUST-3 protocol.

c The residence time at each temperature in the IMPROVE protocol depends on when the flame ionization detector (FID) signal returns to the baseline to achieve well-defined carbon fractions.

the evolution temperature have recently been found useful for estimating the source contributions to suspended particulate matter (PM) (Chow et al., 2004b; Kim and Hopke, 2004a, b, c; Kim et al., 2004; Lee et al., 2003; Maykutt et al., 2003; Strezov et al., 2003; Zhao and Hopke et al., 2004).

This paper describes a method applicable to thermal analysis with optical detection that allows temperature sensors to be calibrated against actual sample temperatures. The method is applied to estimate the deviation of "target" (i.e., protocol or sample) from "measured" (i.e., thermocouple) temperatures for the Desert Research Institute/Oregon Graduate Center thermal/optical carbon analyzer (DRI/OGC, Desert Research Institute, Reno, NV); DRI Model 2001 thermal/optical carbon analyzer (Atmoslytic Inc., Calabasas,
CA); and the Sunset Laboratory Carbon Aerosol Analysis Lab Instrument (Sunset Laboratory, Tigard, OR) to quantify the temperature biases in the current experimental configurations. The effects of these deviations from target temperatures on OC, EC, and thermally-derived carbon fractions are examined. An algorithm is developed using the calibrations to reconcile the target and measured temperatures. Use of this calibration method is expected to allow deviations between laboratories to be better understood, permit study of thermally-derived carbon fractions that might better represent source contributions, and obtain better precision on OC, $\mathrm{EC}$, and carbon fraction measurements. 


\section{Experimental apparatus and procedure}

\subsection{Thermal analysis methods}

OC and EC are removed from sampling substrates (e.g., quartz-fiber filter) by volatilization, and/or combustion at selected temperatures, and by conversion of the released gases to carbon dioxide $\left(\mathrm{CO}_{2}\right)$ or methane $\left(\mathrm{CH}_{4}\right)$, followed by infrared absorption $\left(\mathrm{CO}_{2}\right)$ or flame ionization $\left(\mathrm{CH}_{4}\right)$ detection (Novakov, 1982; Huntzicker et al., 1982; Chow et al., 1993; Turpin et al., 1994; Birch and Cary, 1996). EC is not volatile and is only released by oxidation, typically in an oxygen-containing atmosphere at a temperature above $340^{\circ} \mathrm{C}$ (Cachier et al., 1989a). Most of the atmospheric OC tends to evolve at a lower temperature (e.g., $<550^{\circ} \mathrm{C}$ ) in an oxygenfree atmosphere; therefore, it can be separated from EC. Heating in an inert atmosphere, however, causes certain OC compounds to pyrolyze or char, thereby inflating the atmospheric EC in the sample. In thermal/optical carbon analysis (e.g., Chow et al., 1993, 2001), a red light laser monitors the darkening of the particle deposit on the filter due to OC charring. When the reflected or transmitted light attains its original intensity, the pyrolyzed OC (i.e., OP) is considered to have been removed and the remaining carbon is assumed to be the EC that was originally on the filter. Although the principles of thermal methods appear to be similar, they contain subtle variations with respect to: location of the temperature monitor (i.e., thermocouple) relative to the sample; analysis atmospheres; temperature ramping rates; temperature plateaus; residence time at each plateau; optical pyrolysis monitoring configuration; carrier gas flow through or across the sample; and oven flushing conditions. These differences are not always well-characterized or reported with the analysis results.

The rate of OC volatilization or EC oxidation reaction kinetics can be described by the Arrhenius (1889) equation:

$$
-\left.\frac{1}{[C]} \sum_{i} \frac{d[C]}{d t}\right|_{i}=\sum_{i} k_{i}=\sum_{i} A_{i} \times \exp \left(\frac{-E_{a, i}}{R T}\right)
$$

where:

$[C]=$ total carbon compound concentration

$i=$ reaction of mechanism dependent chemical species

$k_{i}=$ rate constant for reaction $i$

$A_{i}=$ dynamic constant for reaction $i$

$E_{a, i}=$ activation energy for reaction $i$

$R=$ universal gas constant $\left(8.314 \times 10^{-3} \mathrm{~kJ} \mathrm{~mol}^{-1} \mathrm{~K}^{-1}\right)$

$T=$ temperature $\left({ }^{\circ} \mathrm{K}\right)$

where the reaction rate $k_{i}$ (volatilization, pyrolysis, oxidation, etc.) increases nonlinearly with temperature. A significant change in reaction rate occurs as the temperature approaches that of the activation energy (i.e, $E_{a, i} / R$ ), which differs for different chemical compounds. The temperature program influences the evolution of $\mathrm{OC}$ and $\mathrm{EC}$, and possibly the OC/EC split (Chow et al., 2001, 2004a). The rates and quantities of carbon leaving the sample at different temperatures reflect the composition of carbonaceous material in the sample (Chow et al., 2005; Currie et al., 2002). In addition to $\mathrm{OC}$ and $\mathrm{EC}$, temperature-resolved carbon fractions have been reported from major ambient networks. For example, the IMPROVE network that monitors United States national parks, wilderness areas, and wildlife preserves reports eight carbon fractions between $120^{\circ} \mathrm{C}$ and $800^{\circ} \mathrm{C}$ (Table 1). The STN operates in urban areas of the United States and reports four thermally-derived sub-fractions of OC resolved by the analysis temperature program (Table 1).

\subsection{Carbon analyzers}

The DRI/OGC analyzers have been used for thermal/optical reflectance (TOR) analysis of quartz-fiber filter samples acquired from the IMPROVE network and other ambient and source characterization studies since 1986 following the IMPROVE_TOR charring correction protocol (Chow et al., 1993). The Sunset analyzer implements thermal/optical transmission (TOT) charring corrections for the NIOSH (1999), STN (Peterson and Richards, 2002), and the Hong Kong University of Science and Technology (HKUST-3) (Yang and Yu, 2002) thermal protocols. The Model 2001 analyzer implements both the TOR and TOT charring corrections for all temperature protocols. The IMPROVE, STN, and HKUST-3 temperature protocols are documented in Table 1 and instrument configurations are compared in Table 2 . Figure 1 illustrates the location of the temperature sensor relative to the sample for each analyzer. Thermocouples do not contact the sample punch in any of the instruments. Sample temperatures may differ from the thermocouple temperature due to: 1) different thermal properties of the sample and thermocouple; 2) temperature gradients in the sample oven; and/or 3) temperature gradients between the sample oven and the oxidation oven.

The DRI/OGC analyzer uses a Nichrome heating coil (Marchi Associates, SDH 175, Redwood City, CA) that is partially exposed to the ambient air without insulation. The temperature gradient in the sample heating zone varies from $\sim 20^{\circ} \mathrm{C} / \mathrm{cm}$ at $1 \%$ power output to $\sim 50^{\circ} \mathrm{C} / \mathrm{cm}$ at $75 \%$ power output $\left(>600^{\circ} \mathrm{C}\right)$. A shielded Omega Type-K thermocouple (Stamford, CT) serves as both a temperature sensor and a pushrod to which the sample holder is attached. Sample punches are loaded and manually inserted into the heating zone. The thermocouple tip is separated from the sample punch by 2 to $4 \mathrm{~mm}$ (Fig. 1a). The ungrounded Type-K thermocouple requires approximately $18 \mathrm{~s}$ to equilibrate its response at a given temperature plateau.

In the Model 2001 analyzer, the sample punch is placed in a quartz holder oriented parallel to the direction of the carrier gas flow. Sample insertion is controlled by an electric stepper motor that ensures a repeatable sample position in the oven by a pushrod containing the thermocouple. The external shield for this grounded Type-K thermocouple is 
Table 2. Intercomparisons between DRI/OGC, DRI Model 2001, and Sunset Laboratory thermal/optical carbon analyzers.

\begin{tabular}{|c|c|c|c|}
\hline Parameters & DRI/OGC & DRI Model 2001 & Sunset Laboratory \\
\hline Orientation of sample filter & $\begin{array}{l}\text { Vertical. Carrier gas flows per- } \\
\text { pendicular to the filter. }\end{array}$ & $\begin{array}{l}\text { Horizontal. Carrier gas flows } \\
\text { parallel to the filter. }\end{array}$ & $\begin{array}{l}\text { Horizontal. Carrier gas flows } \\
\text { parallel to the filter. }\end{array}$ \\
\hline Sample size & $0.5 \mathrm{~cm}^{2}$ circular punch & $0.5 \mathrm{~cm}^{2}$ circular punch & $1 \mathrm{~cm}^{2}$ rectangular punch \\
\hline Thermocouple & $\begin{array}{l}\text { Shielded Omega Type-K ther- } \\
\text { mocouple. Sheath diameter is } \\
0.32 \mathrm{~cm} \text {. Response time con- } \\
\text { stant is } \sim 18 \mathrm{~s} \text {. }\end{array}$ & $\begin{array}{l}\text { Unshielded (exposed) Omega } \\
\text { Type-K thermocouple. Sheath } \\
\text { diameter is } 0.32 \mathrm{~cm} \text {. Response } \\
\text { time constant is }<1 \mathrm{~s} \text {. }\end{array}$ & $\begin{array}{l}\text { Shielded Omega Type-K ther- } \\
\text { mocouple. Sheath diameter is } \\
0.16 \mathrm{~cm} \text {. Response time con- } \\
\text { stant is } \sim 4 \mathrm{~s} \text {. }\end{array}$ \\
\hline Position of the thermocouple & $\begin{array}{l}\text { Thermocouple is located 2- } \\
4 \text { mm upstream of the center of } \\
\text { sample punch and moves with } \\
\text { the sample. }\end{array}$ & $\begin{array}{l}\text { Thermocouple is located } \\
<2 \mathrm{~mm} \text { underneath the fil- } \\
\text { ter punch and within } 1 \mathrm{~mm} \\
\text { of the center of the punch. } \\
\text { Thermocouple moves with the } \\
\text { sample. }\end{array}$ & $\begin{array}{l}\text { Thermocouple is located } \\
\sim 20 \mathrm{~mm} \text { downstream of the } \\
\text { sample punch and fixed in the } \\
\text { oven. }\end{array}$ \\
\hline Oven design & $\begin{array}{l}\text { Quartz oven. Perpendicular } \\
\text { connection between the sam- } \\
\text { ple and the oxidation oven. } \\
\text { The oven pressure is } \sim 1 \text { PSI. }\end{array}$ & $\begin{array}{l}\text { Quartz oven. Straight con- } \\
\text { nection between the sample } \\
\text { and oxidation oven. A flow- } \\
\text { limiting orifice is installed be- } \\
\text { tween the sample and oxida- } \\
\text { tion oven minimizes backflow } \\
\text { from the catalyst. The oven } \\
\text { pressure is } \sim 3 \text { PSI. }\end{array}$ & $\begin{array}{l}\text { Quartz oven. Straight connec- } \\
\text { tion between the sample and } \\
\text { the oxidation oven. A flow- } \\
\text { limiting orifice is installed be- } \\
\text { tween the sample and oxida- } \\
\text { tion oven. Oven pressure is } \sim 3 \\
\text { PSI. }\end{array}$ \\
\hline Heater design & $\begin{array}{l}\text { Quartz oven wrapped } \\
\text { with custom-made } 650 \mathrm{~W} \\
\text { Nichrome coiled heater } \\
(75 \mathrm{~mm} \text { length } \times 18 \mathrm{~mm} \text { out- } \\
\text { side diameter), with a large } \\
(300 \mathrm{~mm} \text { length } \times 190 \mathrm{~mm} \\
\text { width } \times 190 \mathrm{~mm} \text { height }) \text { fire- } \\
\text { brick block as insulator. Coil } \\
\text { is partially exposed to the air. } \\
\text { Maximum ramping rate is } \\
\sim 5^{\circ} \mathrm{C} / \mathrm{min} \text {. }\end{array}$ & $\begin{array}{l}\text { Two iron-chromium- } \\
\text { aluminum (ICA) heaters } \\
\text { imbedded in firebrick blocks } \\
(63 \mathrm{~mm} \text { length } \times 25 \mathrm{~mm} \\
\text { width } \times 100 \mathrm{~mm} \text { height) shield } \\
\text { both sides of the oven. A } \\
\text { cooling fan is installed under } \\
\text { the oven. Maximum ramping } \\
\text { rate is } \sim 7^{\circ} \mathrm{C} / \mathrm{min} \text {. }\end{array}$ & $\begin{array}{l}\text { Quartz oven wrapped with } \\
\text { heating coils and enclosed in } \\
\text { a case with insulating quartz } \\
\text { wool and pads. Maximum } \\
\text { ramping rate is } \sim 5^{\circ} \mathrm{C} / \mathrm{min} \text {. }\end{array}$ \\
\hline Optical monitoring & $\begin{array}{l}\text { Monitoring reflectance of } \\
\text { sample relative to the initial } \\
\text { value. }\end{array}$ & $\begin{array}{l}\text { Monitoring both reflectance } \\
\text { and transmittance of sample } \\
\text { relative to the initial values or } \\
\text { optical standards. }\end{array}$ & $\begin{array}{l}\text { Monitoring transmittance of } \\
\text { sample relative to the initial } \\
\text { value. }\end{array}$ \\
\hline Sample introduction & $\begin{array}{l}\text { Manual sample introduction } \\
\text { by a pushrod. Manual closing } \\
\text { of the sample port. }\end{array}$ & $\begin{array}{l}\text { Automatic sample introduc- } \\
\text { tion by a stepping motor. Au- } \\
\text { tomatic closure of the sample } \\
\text { port. }\end{array}$ & $\begin{array}{l}\text { Manual sample introduction } \\
\text { by a quartz spatula. Manual } \\
\text { closing of the sample port. }\end{array}$ \\
\hline
\end{tabular}

removed to reduce the response time to less than one second, and the sensor tip is located $<2 \mathrm{~mm}$ under the edge of the filter punch to minimize interference with the reflectance and transmittance measurements (Fig. 1b). Two iron-chromiumaluminum (ICA) heaters are insulated by firebrick blocks to avoid heat dissipation. The temperature sensor is always in the same position relative to the sample, and the sample is in the same part of the oven, until the thermocouple is replaced.
The Sunset Laboratory analyzer locates the sample punch on a transparent quartz spatula that is placed at the same location in the oven. The sample holder has a flat $\left(2 \mathrm{~cm}^{2}\right)$ surface at one end to hold a filter sample and a long stem to facilitate the manual loading of the filter sample into the oven. The quartz oven, which is enclosed in a case insulated with quartz wool and pads, is wrapped by a Nichrome heating coil (Sciare et al., 2003). As shown in Fig. 1c, the thermocouple 
is in a fixed location $\sim 20 \mathrm{~mm}$ downstream of the filter punch center. The sample is placed between two stops on the flat end of the sample holder to ensure its precise position.

In each instrument, the evolved carbon is first converted to $\mathrm{CO}_{2}$ through an oxidizer (manganese dioxide $\left[\mathrm{MnO}_{2}\right]$ at $\sim 900^{\circ} \mathrm{C}$ ). The $\mathrm{CO}_{2}$ is then reduced to $\mathrm{CH}_{4}$ as the carrier gas passes through a granulated firebrick impregnated with nickel catalyst at $\sim 400^{\circ} \mathrm{C}$. The $\mathrm{CH}_{4}$ is then quantified by a flame ionization detector (FID). The FID is operated at a time resolution of one second. The same type of red light $(632.8 \mathrm{~nm})$ helium-neon laser is used for charring correction among the three different models of carbon analyzers.

\subsection{Temperature indicators}

Since it is not possible to sense the temperature of the sample directly, materials were sought that: 1) could be placed where the sample would normally be located and 2) would yield a rapid signal when a known temperature was achieved. Metallic melting point standards (e.g., tin at $232^{\circ} \mathrm{C}$ and zinc at $420^{\circ} \mathrm{C}$ ) exhibit sharp changes in heat capacity, conductivity, and/or viscosity at their phase transition points; however, these properties are not detected by the FID or optics. Organic melting point standards rely on the change in vapor pressure at the phase transition point, and this change can be detected by the FID; however, these compounds often evaporate or sublimate prior to boiling, thereby smearing the FID response. The FID response is further diffused as vapor passes through the oxidation and reduction ovens.

Quick-drying temperature-indicating liquids of different melting points, Tempilaq ${ }^{\circ} \mathrm{G}$ (Tempil Inc., South Plainfield, NJ, USA), are used as temperature indicators in muffle furnaces. A Tempilaq ${ }^{\circ} \mathrm{G}$ liquid contains long-chain hydrocarbons suspended in an organic solvent. Currently, Tempilaq ${ }^{\circ}$ $G$ liquids are manufactured for indicating 44 specific temperatures spanning from 80 to $1100^{\circ} \mathrm{C}$. The accuracy of Tempilaq $^{\circ} \mathrm{G}$ is certified within $\pm 1 \%$ of its designated temperature and is traceable to the National Institute of Standards and Technology (NIST). Tempilaq ${ }^{\circ} \mathrm{G}$ is bottled in liquid form and dries quickly to a dull film when applied to a surface. As the surface is heated to the designated temperature, the film liquefies and is accompanied by a change of appearance that can be optically monitored to determine sample temperature.

\subsection{Standard preparation}

Temperature calibration requires a pre-fired quartz-fiber filter (\#2500 QAT-UP, Pall Life Sciences, Ann Arbor, MI) punch $\left(0.5 \mathrm{~cm}^{2}\right.$ for DRI analyzers and $1.0 \mathrm{~cm}^{2}$ for the Sunset analyzer) and a clean matching-sized quartz glass disk (Continental Glass Engineering, Burbank, CA). Quartz-fiber filter punches are sliced in half with a filter-sectioning device (Fung et al., 2004). A thin layer of Tempilaq ${ }^{\circ} \mathrm{G}(25 \mu \mathrm{L})$ is uniformly applied to the quartz disk surface with a $0.1 \mathrm{ml}$

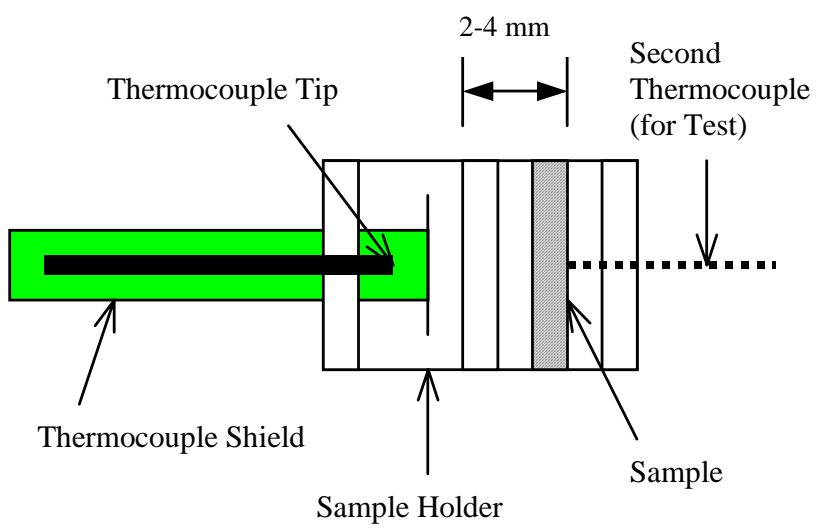

(a)

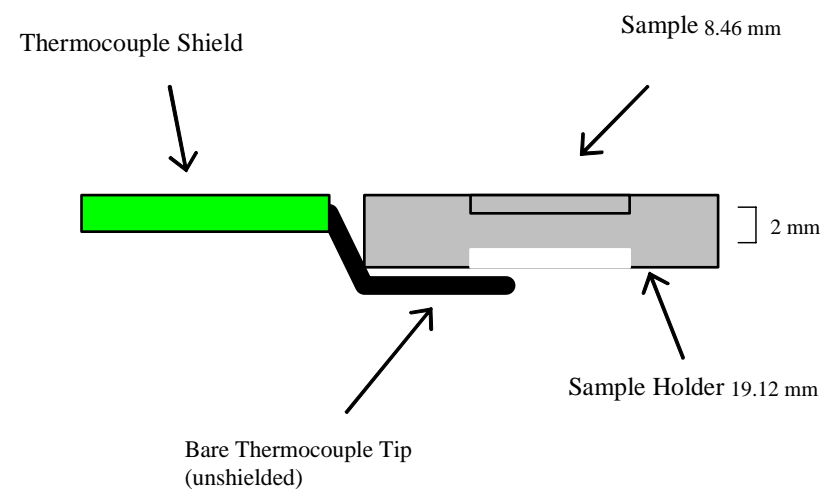

(b)

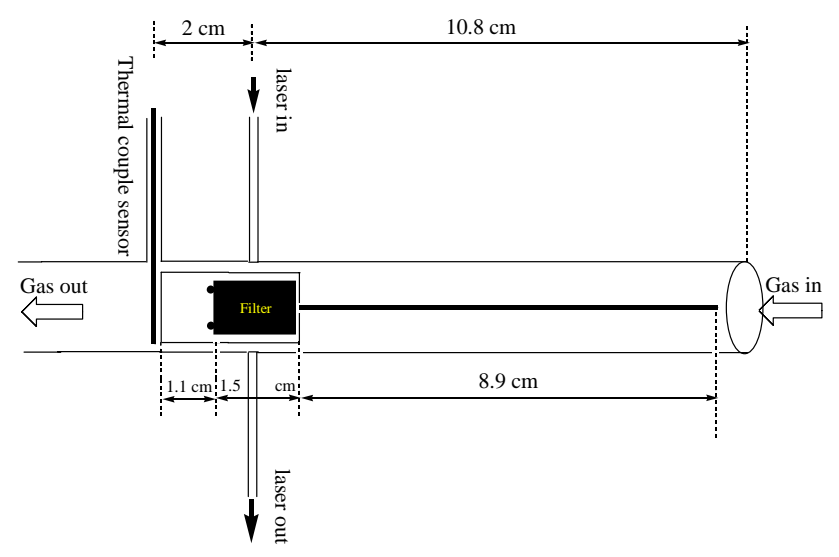

(c)

Fig. 1. Schematic diagram of sample holders for the: (a) Desert Research Institute/Oregon Graduate Center (DRI/OGC) thermal/optical carbon analyzer; (b) DRI Model 2001 thermal/optical carbon analyzer; and (c) Sunset Laboratory Carbon Aerosol Analysis Lab Instrument.

Eppendorf graduated Combitip (Brinkman Instruments Inc., Westbury, NY), and it is immediately (before drying) covered with a sliced filter punch. For cost savings, a glass - instead of quartz - disk can be used for Temiplaq ${ }^{\circ} \mathrm{G}$ at temperatures 


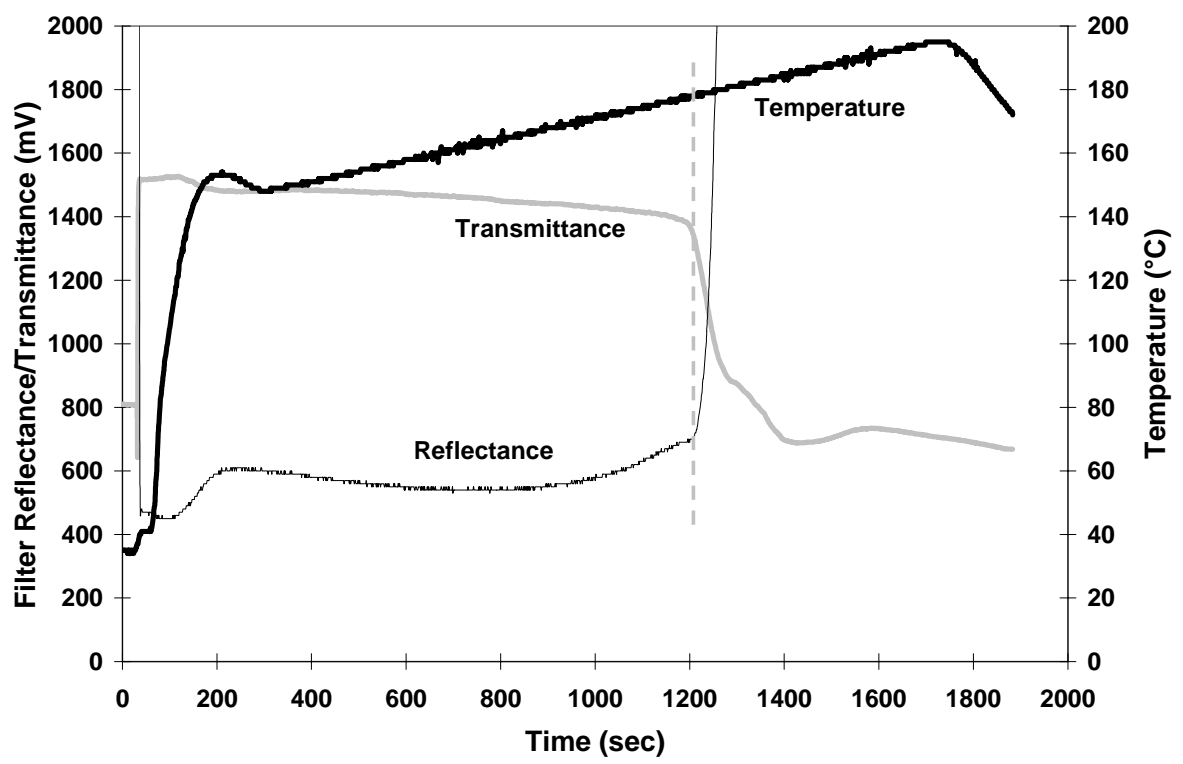

Fig. 2. Temperature ramping with a Tempilaq ${ }^{\circ} \mathrm{G}$ temperature indicator rated at $184^{\circ} \mathrm{C}$ for the DRI Model 2001 carbon analyzer. The vertical dashed line shows where the appearance of the temperature indicator changed, as detected by both reflected and transmitted light.

less than $520^{\circ} \mathrm{C}$. The disk sandwich (i.e., temperature standard) is loaded into the analyzer sample holder for analysis. The coating must be sufficiently heavy to color the filter, but not so heavy as to render the sample opaque to transmitted light.

\subsection{Temperature program}

After insertion of the temperature standard into the analyzer, the temperature is slowly $\left(2{ }^{\circ} \mathrm{C} / \mathrm{min}\right)$ ramped across a $50^{\circ} \mathrm{C}$ range containing the specified Tempilaq $^{\circ} \mathrm{G}$ melting point. This slow ramping creates a quasi-equilibrium condition that allows the phase transition point to be resolved. When the specified temperature is reached, the Tempilaq ${ }^{\circ} \mathrm{G}$ liquefies, causing a sharp change in reflectance and transmittance.

Figure 2 demonstrates the thermocouple temperature, reflectance, and transmittance as a function of analysis time for the calibration temperature program. The reflectance and transmittance remain relatively flat until the temperature approaches its specified value of $184^{\circ} \mathrm{C}$. Figure 3 compares the time series of reflectance, transmittance, and their respective first- and second- order derivatives. The second-order derivative (change in the slope) records the inflection point of reflectance or transmittance that provides the best indication of the attainment of the designated temperature. Thermocouple temperature at this critical point is recorded as "measured" temperature. The temperature deviation $(\Delta T)$ between the sample and the thermocouple temperatures is determined by comparing the rated $\mathrm{Tempilaq}^{\circ} \mathrm{G}$ temperature with this measured value.

In the Model 2001, the reflectance-based method generally gives a lower liquefying temperature than the transmittance- based method, within $\pm 2^{\circ} \mathrm{C}$. Given the uncertainty in the Tempilaq ${ }^{\circ} \mathrm{G}$ temperature rating of $\pm 1 \%$, calibrations based on the two optical methods are considered to be equivalent; therefore, their means are used. Among temperature indicators that achieve an adequate signal/noise ratio, the 121, $184,253,510,649,704$, and $816^{\circ} \mathrm{C}$ mixtures were chosen for IMPROVE protocol temperature calibration, whereas the $121,184,253,510,649$, and $927^{\circ} \mathrm{C}$ mixtures were used for the HKUST-3 protocol. Replicate analyses were performed to evaluate the precision of temperature deviations.

\section{Analysis results and instrument variations}

Five DRI/OGC (CA \#1-\#5), five DRI Model 2001 (CA \#6\#11), and one Sunset analyzers were tested. Tables 3 to 5 summarize the average temperature deviations at each test temperature for the 11 analyzers. A positive temperature deviation indicates that the thermocouple sensor underestimates the sample temperature and vice-versa.

For the Model 2001 analyzers, the sample temperature was $<10^{\circ} \mathrm{C}$ hotter than the sensor reading at the lowest two temperatures $\left(<200^{\circ} \mathrm{C}\right)$, and increased to 20 to $30^{\circ} \mathrm{C}$ hotter at the higher temperatures (Table 3 ). The precision of temperature deviations (i.e., $\sigma_{\Delta T}$ ), determined from the standard deviation of multiple replicate analyses, was generally within $\pm 4^{\circ} \mathrm{C}$. This reflects the consistency of analytical conditions among the five analyzers. Table 3 shows nearly linear relationships between the target and measured temperatures with high correlations. Thus, a constant temperature offset of 3 to $12^{\circ} \mathrm{C}$ can be adjusted in the carbon analyzer software to reflect sample temperatures. 
Table 3. Summary of temperature calibration for five DRI Model 2001 thermal/optical carbon analyzers (CA \#6-11).

\begin{tabular}{|c|c|c|c|c|c|c|c|c|}
\hline Test Date & $\begin{array}{l}\text { Tempilaq }{ }^{\circ} \mathrm{G} \text { Indicator } \\
\text { Temperature }\left({ }^{\circ} \mathrm{C}\right)\end{array}$ & $121 \pm 2$ & $184 \pm 2$ & $253 \pm 3$ & $510 \pm 6$ & $704 \pm 8$ & $816 \pm 9$ & $\begin{array}{l}\text { Slope }(b)^{d} \\
\text { Intercept (a) } \\
\text { Number of Tests (n) } \\
\text { Correlation }\left(r^{2}\right)\end{array}$ \\
\hline \multirow{4}{*}{$2 / 11 / 04$} & DRI 2001 CA\#6 & & & & & & & $\mathrm{b}=0.995 \pm 0.004$ \\
\hline & $\bar{T}^{\mathrm{a}}$ & 112 & 175 & 246 & 499 & 691 & 817 & $a=10.05 \pm 1.83$ \\
\hline & $\Delta T^{\mathrm{b}}$ & $9-10$ & $8-10$ & $6-9$ & $11-12$ & $11-16$ & $-4-1$ & $n=24(4 \times 6)^{e}$ \\
\hline & $\overline{\Delta T} \pm \sigma_{\Delta T}{ }^{\mathrm{c}}$ & $9 \pm 0.5$ & $9 \pm 1$ & $7 \pm 1$ & $11 \pm 1$ & $13 \pm 2$ & $-1 \pm 2$ & $\mathrm{r}^{2}=0.996$ \\
\hline \multirow{4}{*}{$11 / 02 / 04$} & DRI 2001 CA\#7 & & & & & & & $\mathrm{b}=1.012 \pm 0.005$ \\
\hline & $\bar{T} \mathrm{a}$ & 112 & 174 & 230 & 486 & 679 & 800 & $a=12.91 \pm 2.63$ \\
\hline & $\Delta T^{\mathrm{b}}$ & $9-10$ & $9-10$ & $18-28$ & 19-30 & $23-28$ & $10-24$ & $\mathrm{n}=24(4 \times 6)^{\mathrm{e}}$ \\
\hline & $\overline{\Delta T} \pm \sigma_{\Delta T}{ }^{\mathrm{c}}$ & $9 \pm 1$ & $10 \pm 1$ & $23 \pm 4$ & $24 \pm 4$ & $25 \pm 2$ & $16 \pm 6$ & $r^{2}=0.999$ \\
\hline \multirow{4}{*}{$04 / 21 / 04$} & DRI 2001 CA\#9 & & & & & & & $b=1.040 \pm 0.009$ \\
\hline & $\bar{T} \mathrm{a}$ & 116 & 175 & 262 & 482 & 676 & 793 & $\mathrm{a}=-3.00 \pm 4.39$ \\
\hline & $\Delta T^{\mathrm{b}}$ & $4-5$ & $8-9$ & $-10-(-9)$ & $26-29$ & $26-29$ & $22-24$ & $n=18(3 \times 6)^{e}$ \\
\hline & $\overline{\Delta T} \pm \sigma_{\Delta T}{ }^{\mathrm{c}}$ & $5 \pm 1$ & $9 \pm 1$ & $9 \pm 1$ & $28 \pm 2$ & $28 \pm 2$ & $23 \pm 1$ & $\mathrm{r}^{2}=0.998$ \\
\hline \multirow{4}{*}{ 04/19/04 } & DRI 2001 CA\#10 & & & & & & & $\mathrm{b}=1.022 \pm 0.004$ \\
\hline & $\bar{T}$ a & 113 & 174 & 239 & 495 & 678 & 794 & $a=6.55 \pm 2.15$ \\
\hline & $\Delta T^{\mathrm{b}}$ & $7-9$ & $8-14$ & $13-16$ & $12-19$ & $17-34$ & $17-25$ & $\mathrm{n}=18(3 \times 6)^{\mathrm{e}}$ \\
\hline & $\overline{\Delta T} \pm \sigma_{\Delta T}{ }^{\mathrm{c}}$ & $8 \pm 1$ & $10 \pm 3$ & $14 \pm 2$ & $15 \pm 4$ & $26 \pm 7$ & $22 \pm 4$ & $r^{2}=0.999$ \\
\hline \multirow{4}{*}{$11 / 15 / 04$} & DRI 2001 CA\#11 & & & & & & & $\mathrm{b}=1.017 \pm 0.004$ \\
\hline & $\bar{T} \mathrm{a}$ & 116 & 179 & 246 & 490 & 683 & 807 & $a=4.28 \pm 1.95$ \\
\hline & $\Delta T^{\mathrm{b}}$ & $4-5$ & $5-6$ & $6-7$ & $18-21$ & $20-24$ & $9-10$ & $\mathrm{n}=30(5 \times 6)^{\mathrm{e}}$ \\
\hline & $\overline{\Delta T} \pm \sigma_{\Delta T}{ }^{\mathrm{c}}$ & $5 \pm 1$ & $5 \pm 1$ & $7 \pm 0.5$ & $20 \pm 1$ & $21 \pm 2$ & $9 \pm 0.5$ & $\mathrm{r}^{2}=0.999$ \\
\hline
\end{tabular}

a $\bar{T}$ is the average measured temperature.

b $\Delta T$ is the difference between the rated Tempilaq $^{\circ} \mathrm{G}$ (target) and thermocouple (measured) temperatures.

c $\overline{\Delta T} \pm \sigma_{\Delta T}$ indicates the average and standard deviation of $\Delta T$.

${ }^{\mathrm{d}}$ Rated Tempilaq ${ }^{\circ} \mathrm{G}$ temperature $(\mathrm{Y})$ versus thermocouple temperature $(\mathrm{X})$.

e Number of replicates times the number of temperature plateaus.

Temperature tests for DRI/OGC analyzers contain two analyses in which $\Delta T$ for both the maximum and minimum sample-to-thermocouple distances were determined. Table 4 shows that the sample temperature was 10 to $50^{\circ} \mathrm{C}$ hotter than the sensor readings at all temperature ranges, except for CA \#1, where a $\Delta T$ of $57-77^{\circ} \mathrm{C}$ was found for the highest temperature $\left(704^{\circ} \mathrm{C}\right)$. Besides inter-analyzer differences, temperatures varied by more than $20^{\circ} \mathrm{C}$ in replicate tests for a given analyzer. This variability exceeds the uncertainty of Tempilaq ${ }^{\circ} \mathrm{G}( \pm 1 \%)$. The linear regression of this rated Tempilaq ${ }^{\circ} \mathrm{G}$ (target) temperature against thermocouple (measured) temperature yields slopes and intercepts that are associated with larger standard deviations (Table 4). According to Eq. (1), the effect of temperature bias may be more pronounced at lower temperatures.

For the Sunset analyzer, the sample temperature was 12 to $33^{\circ} \mathrm{C}$ hotter than the sensor reading for the two lowest and highest temperatures, and 2 to $11^{\circ} \mathrm{C}$ cooler for the two mid- dle temperatures. The good reproducibility $(\sim \pm 1 \%)$ for the Sunset and Model 2001 analyzers is sufficient to confirm differences between the target and measured temperatures.

\section{Temperature calibration}

Temperature bias during thermal carbon analysis can vary among different designs of instruments, within the same model of analyzer, and among replicate analyses. Periodic temperature calibration and performance testing is needed to achieve good reproducibility of carbon fraction measurements. Linear calibration curves can be generated, as illustrated in Fig. 4.

$T_{\text {sample(target) }}=b \times T_{\text {thermocouple(measured) }}+a$

where $T_{\text {sample(target) }}$ is the set point temperature specified by the analytical protocols and $T_{\text {thermocouple(measured) }}$ is the sensor reading of a thermocouple. Variables $a$ and $b$ are the 
Table 4. Summary of temperature calibration for five DRI/OGC thermal/optical carbon analyzers (CA \#1-5).

\begin{tabular}{|c|c|c|c|c|c|c|c|c|}
\hline Test Date & $\begin{array}{l}\text { Tempilaq }^{\circ} \mathrm{G} \text { Indicator } \\
\text { Temperature }\left({ }^{\circ} \mathrm{C}\right)\end{array}$ & $121 \pm 2$ & $184 \pm 2$ & $253 \pm 3$ & $510 \pm 6$ & $704 \pm 8$ & $816 \pm 9$ & $\begin{array}{l}\text { Slope }(b)^{d} \\
\text { Intercept (a) } \\
\text { Number of Tests (n) } \\
\text { Correlation }\left(\mathrm{r}^{2}\right)\end{array}$ \\
\hline 03/17/04 & $\begin{array}{l}\text { DRI/OGC CA\#1 } \\
\bar{T}^{\mathrm{a}} \\
\Delta T^{\mathrm{b}}\end{array}$ & $\begin{array}{l}84 \\
36-37\end{array}$ & $\begin{array}{l}147 \\
33-41\end{array}$ & $\begin{array}{l}209 \\
37-51\end{array}$ & $\begin{array}{l}469 \\
40-43\end{array}$ & $\begin{array}{l}637 \\
57-77\end{array}$ & $\begin{array}{l}\mathrm{N} / \mathrm{A}^{c} \\
\mathrm{~N} / \mathrm{A}\end{array}$ & $\begin{array}{l}\mathrm{b}=1.03 \pm 0.028 \\
\mathrm{a}=32.99 \pm 10.52 \\
\mathrm{n}=10(2 \times 5)^{\mathrm{e}} \\
\mathrm{r}^{2}=0.994\end{array}$ \\
\hline 03/18/04 & $\begin{array}{l}\text { DRI/OGC CA\#2 } \\
\bar{T}^{\mathrm{a}} \\
\Delta T^{\mathrm{b}}\end{array}$ & $\begin{array}{l}103 \\
14-22\end{array}$ & $\begin{array}{l}162 \\
22-23\end{array}$ & $\begin{array}{l}230 \\
23-25\end{array}$ & $\begin{array}{l}480 \\
30-32\end{array}$ & $\begin{array}{l}676 \\
26-30\end{array}$ & $\begin{array}{l}\text { N/A } \\
\text { N/A }\end{array}$ & $\begin{array}{l}\mathrm{b}=1.02 \pm 0.005 \\
\mathrm{a}=18.99 \pm 2.11 \\
\mathrm{n}=10(2 \times 5)^{\mathrm{e}} \\
\mathrm{r}^{2}=0.999\end{array}$ \\
\hline $03 / 22 / 04$ & $\begin{array}{l}\text { DRI/OGC CA\#3 } \\
T^{\mathrm{a}} \\
\Delta T^{\mathrm{b}}\end{array}$ & $\begin{array}{l}110 \\
9-14\end{array}$ & $\begin{array}{l}170 \\
11-18\end{array}$ & $\begin{array}{l}237 \\
11-22\end{array}$ & $\begin{array}{l}482 \\
22-34\end{array}$ & $\begin{array}{l}672 \\
26-38\end{array}$ & $\begin{array}{l}\text { N/A } \\
\text { N/A }\end{array}$ & $\begin{array}{l}\mathrm{b}=1.04 \pm 0.009 \\
\mathrm{a}=8.13 \pm 3.44 \\
\mathrm{n}=10(2 \times 5)^{\mathrm{e}} \\
\mathrm{r}^{2}=0.999\end{array}$ \\
\hline $03 / 23 / 04$ & $\begin{array}{l}\text { DRI/OGC CA\#4 } \\
T^{\mathrm{a}} \\
\Delta T^{\mathrm{b}}\end{array}$ & $\begin{array}{l}107 \\
11-17\end{array}$ & $\begin{array}{l}166 \\
16-20\end{array}$ & $\begin{array}{l}244 \\
8-20\end{array}$ & $\begin{array}{l}493 \\
15-20\end{array}$ & $\begin{array}{l}682 \\
18-28\end{array}$ & $\begin{array}{l}\text { N/A } \\
\text { N/A }\end{array}$ & $\begin{array}{l}\mathrm{b}=1.01 \pm 0.007 \\
\mathrm{a}=13.17 \pm 2.92 \\
\mathrm{n}=10(2 \times 5)^{\mathrm{e}} \\
\mathrm{r}^{2}=0.999\end{array}$ \\
\hline $03 / 24 / 04$ & $\begin{array}{l}\text { DRI/OGC CA\#5 } \\
\bar{T}^{\mathrm{a}} \\
\Delta T^{\mathrm{b}}\end{array}$ & $\begin{array}{l}98 \\
21-26\end{array}$ & $\begin{array}{l}155 \\
27-33\end{array}$ & $\begin{array}{l}219 \\
33-36\end{array}$ & $\begin{array}{l}473 \\
27-48\end{array}$ & $\begin{array}{l}656 \\
43-53\end{array}$ & $\begin{array}{l}\text { N/A } \\
\text { N/A }\end{array}$ & $\begin{array}{l}\mathrm{b}=1.04 \pm 0.010 \\
\mathrm{a}=23.21 \pm 4.02 \\
\mathrm{n}=10(2 \times 5)^{\mathrm{e}} \\
\mathrm{r}^{2}=0.999\end{array}$ \\
\hline
\end{tabular}

a $\bar{T}$ is the average measured temperature.

b $\Delta T$ is the difference between the rated Tempilaq ${ }^{\circ} \mathrm{G}$ (target) and thermocouple (measured) temperatures.

c The DRI/OGC analyzer has a maximum temperature of $800^{\circ} \mathrm{C}$.

${ }^{\mathrm{d}}$ Rated Tempilaq ${ }^{\circ} \mathrm{G}$ temperature $(\mathrm{Y})$ versus thermocouple temperature $(\mathrm{X})$.

e Number of replicates times the number of temperature plateaus.

Table 5. Summary of temperature calibration for the Sunset Laboratory Carbon Aerosol Analysis Lab Instrument.

\begin{tabular}{|c|c|c|c|c|c|c|c|c|}
\hline Test Date & $\begin{array}{l}\text { Tempilaq }^{\circ} \mathrm{G} \text { Indicator } \\
\text { Temperature }\left({ }^{\circ} \mathrm{C}\right)\end{array}$ & $121 \pm 2$ & $184 \pm 2$ & $253 \pm 3$ & $510 \pm 6$ & $649 \pm 7$ & $927 \pm 9$ & $\begin{array}{l}\text { Slope }(b)^{d} \\
\text { Intercept }(a) \\
\text { Number of Tests (n) } \\
\text { Correlation }\left(r^{2}\right)\end{array}$ \\
\hline \multirow{4}{*}{$10 / 13 / 04$} & Sunset Inc. Instrument & & & & & & & $\mathrm{b}=0.989 \pm 0.013$ \\
\hline & $\bar{T} \mathrm{a}$ & 95 & 152 & 253 & 519 & 619 & 912 & $a=20.32 \pm 6.72$ \\
\hline & $\Delta T^{\mathrm{b}}$ & $24-29$ & $32-33$ & $-2-2$ & $-11--7$ & $29-30$ & $12-17$ & $\mathrm{n}=18(3 \times 6)^{\mathrm{e}}$ \\
\hline & $\overline{\Delta T} \pm \sigma_{\Delta T}{ }^{\mathrm{c}}$ & $26 \pm 3$ & $28 \pm 1$ & $0 \pm 2$ & $-9 \pm 2$ & $30 \pm 3$ & $15 \pm 3$ & $r^{2}=0.997$ \\
\hline
\end{tabular}

a $\bar{T}$ is the average measured temperature.

${ }^{\mathrm{b}} \Delta T$ is the difference between the rated Tempilaq ${ }^{\circ} \mathrm{G}$ (target) and thermocouple (measured) temperatures.

${ }^{\mathrm{c}}$ Indicates the average and standard deviation of $\Delta T$.

${ }^{\mathrm{d}}$ Rated $\mathrm{Tempilaq}^{\circ} \mathrm{G}$ temperature (Y) versus thermocouple temperature (X).

e The $927^{\circ} \mathrm{C}$ standard was used in place of the $816^{\circ} \mathrm{C}$ standard to better represent the larger temperature range spanned by the HKUST-3 temperature protocol. 


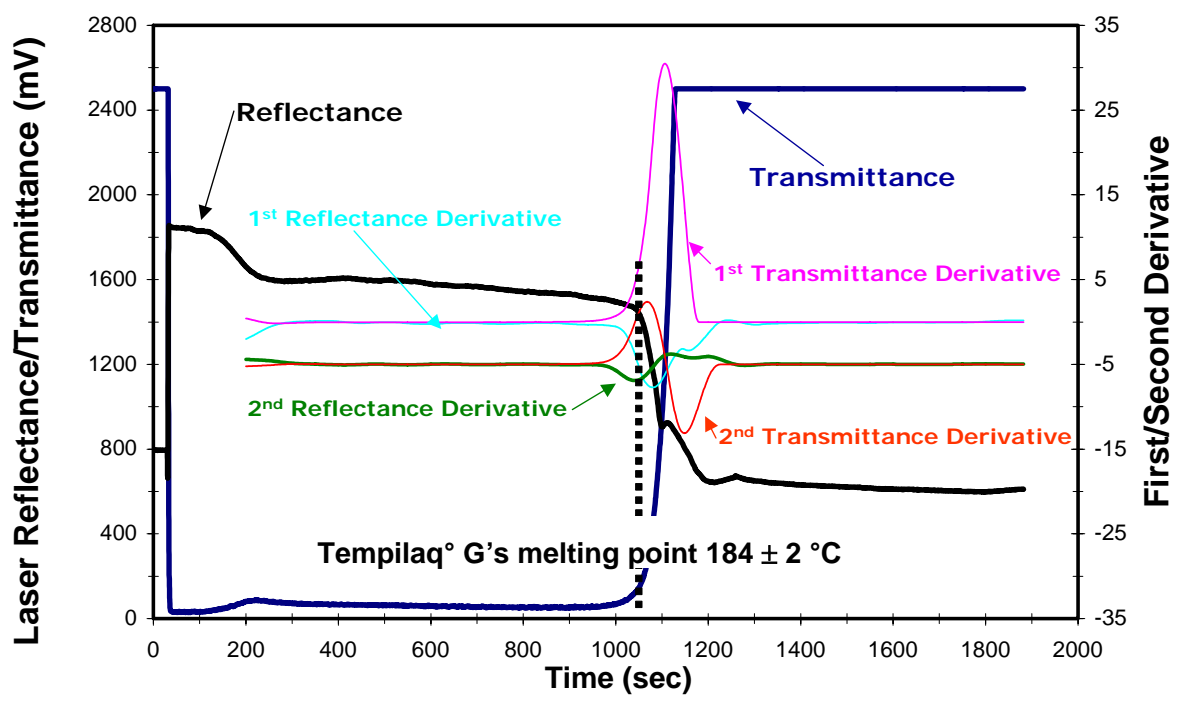

(Tempilaq's melting point $184 \pm 2 \stackrel{\circ}{ }$ C)

Fig. 3. Reflectance and transmittance measurements and their first and second derivatives over time with a Tempilaq $^{\circ} \mathrm{G}$ temperature indicator rated at $184^{\circ} \mathrm{C}$ (Fig. 2). The vertical dashed line indicates the achievement of the rated target temperature.
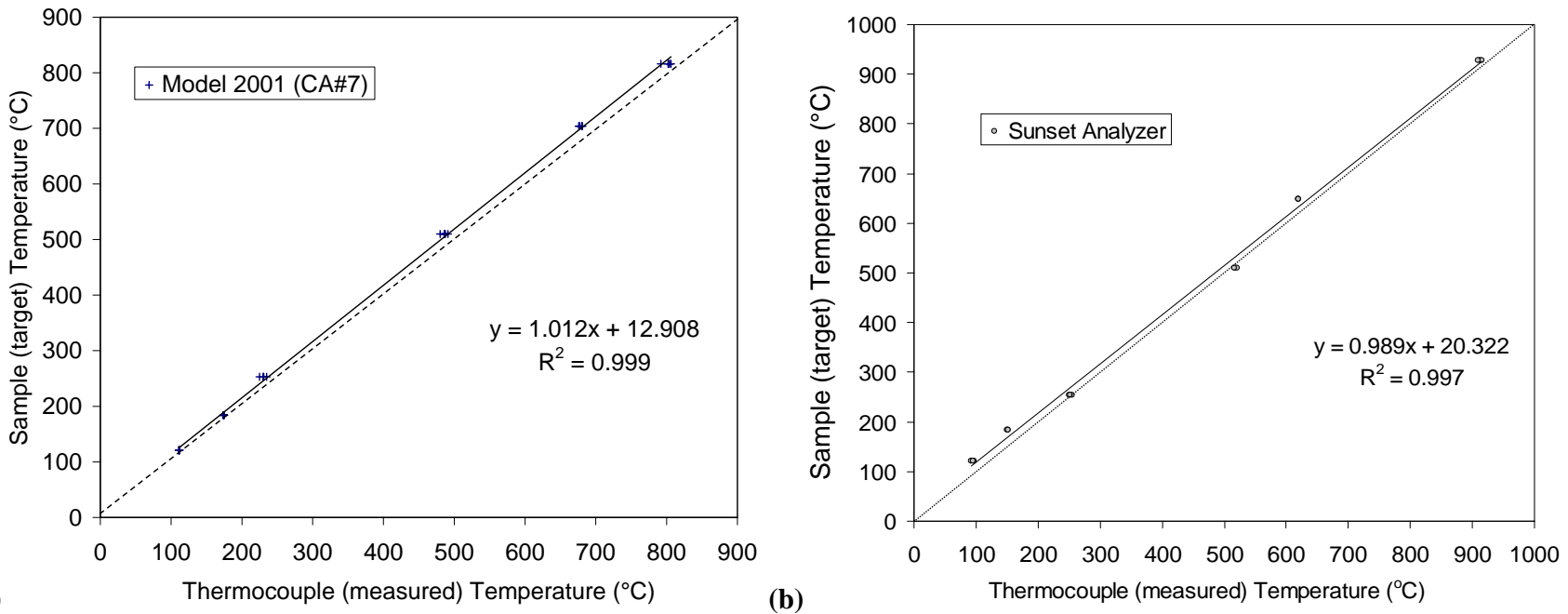

Fig. 4. Linear regression of sample (target) temperature against thermocouple (measured) temperature for the: (a) DRI Model 2001 (CA \#7); and (b) Sunset Laboratory carbon analyzers.

intercept and slope, respectively, and are determined from the least-square linear regression between the target and measured temperatures from the tests. Set-point temperatures can be adjusted so that $T_{\text {sample }}=T_{\text {thermocouple }}$, or the software can be modified to accommodate the calibration. In either case, the temperature reported should reflect the sample temperature, not the thermocouple temperature.

Five ambient samples acquired from the Fresno Supersite (Watson et al., 2000) were analyzed by a Model 2001 analyzer with and without the adjustment after the temperature calibration. These samples represent an urban environment where contributions from vegetative burning, cooking, gasoline- and diesel-vehicle exhaust, and secondary organic aerosol vary throughout the year (Poore, 2002; Schauer and Cass, 2000; Watson and Chow, 2002a, b; Watson et al., 2000, 2002). TC concentrations of the five samples ranged from 3.5 to $15 \mu \mathrm{g} \mathrm{m}^{-3}$. Figure 4 shows that $T_{\text {thermocouple }}$ underestimates $T_{\text {sample }}$; deviations from linearity suggest temperature inhomogeneity in the heating zone. Based on the temperature calibration results, the samples 


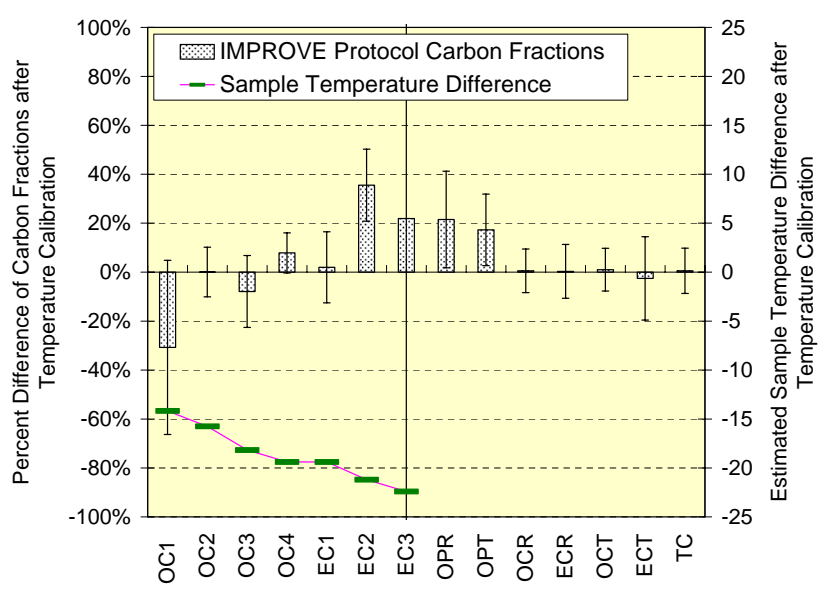

Fig. 5. Changes in carbon fractions after adjustment for temperature calibration (Fig.4) with the DRI Model 2001 carbon analyzer (CA\#7). Statistics are based on average and standard deviation of analysis results of five ambient samples from the Fresno Supersite (TC: $3.5-15 \mu \mathrm{g} \mathrm{m}^{-3}$ ). Sample (target) temperature is lowered by 14 to $22^{\circ} \mathrm{C}$ after the calibration. Carbon fractions are defined in Table 1.

were re-analyzed using a modified IMPROVE protocol in which the temperature was lowered by 14 to $22^{\circ} \mathrm{C}$. Figure 5 shows that while these temperature deviations did not change the OC/EC split for TOR or TOT, cooler temperatures reduced the low temperature $\mathrm{OC}$ fractions (OC1-OC3) and increased the high temperature OC4 and EC fractions. After the adjustment based on temperature calibration, the average changes in $\mathrm{OC} 1\left(120^{\circ} \mathrm{C}\right)$ and $\mathrm{EC} 2\left(700^{\circ} \mathrm{C}\right)$ exceeded $30 \%$, partially due to low carbon concentrations in these carbon fractions. OC1 represents semi-volatile organics, which are possibly adsorbed organic vapors. Charred OC (by reflectance or transmittance) increased by $\sim 20 \%$ when the sample temperature was lowered by 14 to $22^{\circ} \mathrm{C}$.

Lower analysis temperatures (after calibration) did not change the OC/EC split for these examples, and the reduced $\mathrm{OC} 1$ and $\mathrm{OC} 3$ fractions were compensated by the inflated pyrolysis fraction. While carbon fraction measurements may vary between different analyzers due to uncertain analysis temperatures, this study shows that the OC/EC split through optical charring correction is less perturbed, at least for the IMPROVE_TOR protocol. The transmittance-based charring correction may be more dependent on analysis temperatures owing to charring of adsorbed organic vapors within the filter that affect transmittance more than reflectance from the surface deposit (Chow et al., 2004a; Chen et al., 2004)

\section{Summary and conclusions}

A method has been presented that can relate the sample temperature to the sensor temperature in thermal/optical carbon analyzers. It uses temperature-sensitive compounds that change their appearance when they reach a target temperature.

Five to six temperature indicators, covering a range of 120 to $930^{\circ} \mathrm{C}$, were used to evaluate the temperature measures in three different carbon analyzer models: the DRI/OGC, DRI Model 2001, and Sunset analyzers. Thermocouple sensors often underestimated the sample temperature; however, the bias in the DRI Model 2001 tended to be smaller and more consistent $\left(<10^{\circ} \mathrm{C}\right.$ for temperatures $<200^{\circ} \mathrm{C}$ and $<20$ to $30^{\circ} \mathrm{C}$ for higher temperatures). There was a linear relationship between target and measured temperatures with high correlation. The DRI/OGC analyzer reported temperatures that were 10 to $50^{\circ} \mathrm{C}$ lower than the target sample temperatures, and that varied by as much as $20^{\circ} \mathrm{C}$ for replicate analysis. The temperature bias in the Sunset analyzer used in this test was less than $30^{\circ} \mathrm{C}$, but it did not appear to be as linearly related to the target temperatures as the other analyzers.

Even though temperature variations of up to $50^{\circ} \mathrm{C}$ do not appear to alter the OC and EC concentrations with the IMPROVE thermal protocol, they do change the abundances of different carbon fractions from thermal/optical analysis. When applied to ambient samples from the urban Fresno Supersite, a calibration that corrected for a 14 to $22^{\circ} \mathrm{C}$ positive bias resulted in changes greater than $30 \%$ in the IMPROVE protocol for low temperature $\mathrm{OC}\left(\mathrm{OC} 1\right.$ at $\left.120^{\circ} \mathrm{C}\right)$ and high temperature $\mathrm{EC}\left(\mathrm{EC} 2\right.$ at $\left.700^{\circ} \mathrm{C}\right)$ fractions. Refining temperature measures in thermal/optical analysis for trends networks is necessary to ensure the consistency of carbon fraction measurements. This will reduce the degree of misinterpretation of the data in the future. The techniques developed in this study can reduce variability in thermal/optical analysis and be systematized into procedures that are applicable to a wide variety of instruments.

Acknowledgements. This work was sponsored in part by the National Park Service IMPROVE Carbon Analysis Contract No. C2350000894, the U.S. Environmental Protection Agency STAR Grant No. RD-83108601-0, and the Fresno Supersite U.S. EPA Cooperative Agreement No. R-82805701. The conclusions are those of the authors and do not necessarily reflect the views of the sponsoring agencies. Any mention of commercially available products and supplies does not constitute an endorsement of these products and supplies. The authors wish to thank T. Bohannan of the Desert Research Institute (DRI) for assisting with the temperature calibration and J. Gerrard, E. Dieterle, and P. T. Richard of DRI for assembling and editing the manuscript.

Edited by: R. Hitzenberger 


\section{References}

Arrhenius, S.: Über die Reaktionsgeschwindigkeit bei der Inversion von Rohzucker durch Säuren, Z. Phys. Chem., 4 (26), 226-248, 1889.

Birch, M. E. and Cary, R. A.: Elemental carbon-based method for monitoring occupational exposures to particulate diesel exhaust, Aerosol Sci. Technol., 25 (3), 221-241, 1996.

Cachier, H., Bremond, M. P., and Buat-Ménard, P.: Thermal separation of soot carbon, Aerosol Sci. Technol., 10 (2), 358-364, 1989a.

Cachier, H., Bremond, M. P., and Buat-Ménard, P.: Determination of atmospheric soot carbon with a simple thermal method, Tellus, 41B (3), 379-390, 1989b.

Cadle, S. H. and Groblicki, P. J.: An evaluation of methods for the determination of organic and elemental carbon in particulate samples, in: Particulate Carbon: Atmospheric Life Cycles, edited by: Wolff, G. T. and Klimisch, R. L., Plenum Press, New York, NY, 89-109, 1982.

Cao, J. J., Lee, S. C., Zhang, X. Y., Chow, J. C., An, Z. S., Ho, K. F., Watson, J. G., Fung, K. K., Wang, Y. Q., and Shen, Z. $\mathrm{X}$.: Characterization of airborne carbonate over a site near Asian dust source regions during spring 2002 and its climatic and environmental significance, J. Geophys. Res., 110 (D03203), 1-8, 2005.

Chen, L.-W. A., Chow, J. C., Watson, J. G., Moosmüller, H., and Arnott, W. P.: Modeling reflectance and transmittance of quartzfiber filter samples containing elemental carbon particles: Implications for thermal/optical analysis, J. Aerosol Sci., 35 (6), 765-780, 2004.

Chow, J. C., Watson, J. G., Pritchett, L. C., Pierson, W. R., Frazier, C. A., and Purcell, R. G.: The DRI Thermal/Optical Reflectance carbon analysis system: Description, evaluation and applications in U.S. air quality studies, Atmos. Environ., 27A (8), 1185-1201, 1993.

Chow, J. C., Watson, J. G., Crow, D., Lowenthal, D. H., and Merrifield, T.: Comparison of IMPROVE and NIOSH carbon measurements, Aerosol Sci. Technol., 34 (1), 23-34, 2001.

Chow, J. C. and Watson, J. G.: $\mathrm{PM}_{2.5}$ carbonate concentrations at regionally representative Interagency Monitoring of Protected Visual Environment sites, J. Geophys. Res., 107 (D21), ICC 61-ICC 6-9, 2002.

Chow, J. C., Watson, J. G., Chen, L.-W. A., Arnott, W. P., Moosmüller, H., and Fung, K. K.: Equivalence of elemental carbon by Thermal/Optical Reflectance and Transmittance with different temperature protocols, Environ. Sci. Technol., 38(16), 4414-4422, 2004a.

Chow, J. C., Watson, J. G., Kuhns, H. D., Etyemezian, V., Lowenthal, D. H., Crow, D. J., Kohl, S. D., Engelbrecht, J. P., and Green, M.C.: Source profiles for industrial, mobile, and area sources in the Big Bend Regional Aerosol Visibility and Observational (BRAVO) Study, Chemosphere, 54 (2), 185-208, $2004 \mathrm{~b}$.

Chow, J. C., Watson, J. G., Louie, P. K. K., Chen, L.-W. A., and Sin, D.: Comparison of $\mathrm{PM}_{2.5}$ carbon measurement methods in Hong Kong, China, Environ. Poll., 137, 334-344, 2005.

Currie, L. A., Benner Jr., B. A., Cachier, H., Cary, R., Chow, J. C., Druffel, E. R. M., Eglinton, T. I., Gustafsson, Ö., Hartmann, P. C., Hedges, J. I., Kessler, J. D., Kirchstetter, T. W., Klinedinst, D. B., Klouda, G. A., Marolf, J. V., Masiello, C. A., Novakov, T., Pearson, A., Prentice, K. M., Puxbaum, H., Quinn, J. G., Reddy,
C. M., Schmid, H., Slater, J. F., Watson, J. G., and Wise, S. A.: A critical evaluation of interlaboratory data on total, elemental, and isotopic carbon in the carbonaceous particle reference material, NIST SRM 1649a, J. Res. National Bureau Standards, 107 (3), 279-298, 2002.

Fung, K., Chow, J. C., Watson, J. G., and Chen, L. Y. A.: Determining organic carbon adsorption on quartz fiber filters by sample splitting and thermal/optical analysis, Proceedings, 13th World Clean Air and Environmental Protection Congress and Exhibition, London, UK, 26 August 2004.

Hitzenberger, R., Jennings, S. G., Larson, S. M., Dillner, A., Cachier, H., Galambos, Z., Rouc, A., and Spain, T. G.: Intercomparison of measurement methods for black carbon aerosols, Atmos. Environ., 33 (17), 2823-2833, 1999.

Huntzicker, J. J., Johnson, R. L., Shah, J. J., and Cary, R. A.: Analysis of organic and elemental carbon in ambient aerosols by a thermal-optical method, in: Particulate Carbon: Atmospheric Life Cycle, edited by: Wolff, G. T. and Klimisch, R. L., Plenum Press, New York, NY, 79-88, 1982.

Jacobson, M. Z.: Strong radiative heating due to the mixing state of black carbon in atmospheric aerosols, Nature, 409, 695-697, 2001.

Kim, E. and Hopke, P. K.: Comparison between conditional probability function and nonparametric regression for fine particle source directions, Atmos. Environ., 38 (28), 4667-4673, 2004a.

Kim, E. and Hopke, P. K.: Source apportionment of fine particles at Washington, DC, utilizing temperature-resolved carbon fractions, JAWMA, 54 (7), 773-785, 2004b.

Kim, E. and Hopke, P. K.: Improving source identification of fine particles in a rural northeastern US area utilizing temperatureresolved carbon fractions, J. Geophys. Res., 109 (D9), D09204, 2004c.

Kim, E., Hopke, P. K., and Edgerton, E. S.: Improving source identification of Atlanta aerosol using temperature resolved carbon fractions in positive matrix factorization, Atmos. Environ., 38 (20), 3349-3362, 2004.

Lavoisier, A.: Chapter 7. In Traite Elementaire de Chimie, Volume 2, Paris, France, 493-501, 1789.

Lee, P. K. H., Brook, J. R., Dabek-Zlotorzynska, E., and Mabury, S. A.: Identification of the major sources contributing to $\mathrm{PM}_{2.5}$ observed in Toronto, Environ. Sci. Technol., 37 (21), 4831-4840, 2003.

MacKenzie, R. C.: Differential Thermal Analysis, Vol. 1, Fundamental Aspects, Academic Press, New York, NY, 1970.

Maykut, N. N., Lewtas, J., Kim, E., and Larson, T. V.: Source apportionment of $\mathrm{PM}_{2.5}$ at an urban IMPROVE site in Seattle, Washington, Environ. Sci. Technol., 37 (22), 5135-5142, 2003.

NIOSH: Method 5040 Issue 3 (Interim): Elemental carbon (diesel exhaust), in: NIOSH Manual of Analytical Methods; National Institute of Occupational Safety and Health: Cincinnati, OH, 1999.

Novakov, T.: Soot in the atmosphere, in: Particulate Carbon: Atmospheric Life Cycle, edited by: Wolff, G. T. and Klimisch, R. L., Plenum Press, New York, NY, 19-41, 1982.

Peterson, M. R. and Richards, M. H.: Thermal-opticaltransmittance analysis for organic, elemental, carbonate, total carbon, and OCX2 in $\mathrm{PM}_{2.5}$ by the EPA/NIOSH method, in: Proceedings, Symposium on Air Quality Measurement Methods and Technology-2002, edited by: Winegar, E. D. and Tropp, R. 
J., Air \& Waste Management Association, Pittsburgh, PA, 83-183-19, 2002.

Poore, M. W.: Levoglucosan in $\mathrm{PM}_{2.5}$ at the Fresno Supersite, JAWMA, 52 (1), 3-4, 2002.

Schauer, J. J. and Cass, G. R.: Source apportionment of wintertime gas-phase and particle-phase air pollutants using organic compounds as tracers, Environ. Sci. Technol., 34 (9), 1821-1832, 2002.

Schmid, H. P., Laskus, L., Abraham, H. J., Baltensperger, U., Lavanchy, V. M. H., Bizjak, M., Burba, P., Cachier, H., Crow, D., Chow, J. C., Gnauk, T., Even, A., ten Brink, H. M., Giesen, K. P., Hitzenberger, R., Hueglin, C., Maenhaut, W., Pio, C. A., Puttock, J., Putaud, J. P., Toom-Sauntry, D., and Puxbaum, H.: Results of the "Carbon Conference" international aerosol carbon round robin test: Stage 1, Atmos. Environ., 35 (12), 2111-2121, 2001.

Sciare, J., Cachier, H., Oikonomou, K., Ausset, P., Sarda-Esteve, R., and Mihalopoulos, N.: Characterization of carbonaceous aerosols during the MINOS campaign in Crete, July-August 2001: A multi-analytical approach, Atmos. Chem. Phys., 3, 1743-1757, 2003,

\section{SRef-ID: 1680-7324/acp/2003-3-1743.}

Strezov, V., Moghtaderi, B., and Lucas, J. A.: Thermal study of decomposition of selected biomass samples, J. Thermal Anal. \& Calorimetry, 72 (3), 1041-1048, 2003.

Turpin, B. J., Huntzicker, J. J., and Hering, S. V.: Investigation of organic aerosol sampling artifacts in the Los Angeles Basin, Atmos. Environ., 28 (19), 3061-3071, Research \& Development, 1994.
Vedal, S.: Critical review - Ambient particles and health: Lines that divide, JAWMA, 47 (5), 551-581, 1997.

Watson, J. G., Chow, J. C., Bowen, J. L., Lowenthal, D. H., Hering, S., Ouchida, P., and Oslund, W.: Air quality measurements from the Fresno Supersite, JAWMA, 50 (8), 1321-1334, 2000.

Watson, J. G.: Visibility: Science and regulation, JAWMA, 52 (6), 628-713, 2002.

Watson, J. G. and Chow, J. C.: A wintertime $\mathrm{PM}_{2.5}$ episode at the Fresno, CA, Supersite, Atmos. Environ., 36 (3), 465-475, 2002a.

Watson, J. G. and Chow, J. C.: Comparison and evaluation of insitu and filter carbon measurements at the Fresno Supersite, J. Geophys. Res., 107 (D21), ICC 3-1-ICC 3-15, 2002 b.

Watson, J. G., Chow, J. C., Lowenthal, D. H., Stolzenburg, M. R., Kreisberg, N. M., and Hering, S. V.: Particle size relationships at the Fresno supersite; JAWMA, 52 (7), 822-827, 2002.

Watson, J. G., Chow, J. C., and Chen, L.-W. A.: Summary of organic and elemental/black carbon analysis methods and intercomparisons, Aerosol and Air Quality Research, 5 (10), 69-109, 2005.

Yang, H. and Yu, J. Z.: Uncertainties in charring correction in the analysis of elemental and organic carbon in atmospheric particles by thermal/optical methods, Environ. Sci. Technol., 36 (23), 5199-5204, 2002.

Zhao, W. X. and Hopke, P. K.: Source apportionment for ambient particles in the San Gorgonio wilderness, Atmos. Environ., 38 (35), 5901-5910, 2004. 